\title{
Orientation by Jumping Spiders of the Genus Phidippus (Araneae: Salticidae) During the Pursuit of Prey
}

\author{
David Edwin Hill \\ Section of Neurobiology and Behavior, Langmuir Laboratory, \\ Cornell University, Ithaca, New York 14850, USA \\ Received September 18, 1978
}

Summary. 1. Jumping spiders of the genus Phidippus tend to occupy waiting positions on plants during the day. From such reconnaissance positions, the spiders often utilize an indirect route of access (detour) to attain a position from which sighted prey (the primary objective of pursuit) can be captured.

2. Selection of an appropriate route of access is based upon movement toward a visually determined secondary objective (part of a plant) which may provide access to the prey position (Fig. 2, Table 1).

3. During pursuit, the spider retains a memory of the relative position of the prey at all times. This memory of prey position is frequently expressed in the form of a reorientation turn to face the expected position of the prey (Fig. 1). Each reorientation can be considered to initiate a new segment of the pursuit.

4. Phidippus employ the immediate direction (or route) of pursuit as a reference direction, for the determination of prey position (Figs. 3 and 4). The spider compensates for its own movement in determining the direction of the prey from a new position (Fig. 5).

5 . The spider retains a memory of the prey direction with reference to gravity (Fig. 6); this memory of the inclination of prey direction can take precedence over conflicting information based upon the use of the route as a reference direction (Figs. 7 and 8).

6. Visual cues provided by both the background and the immediate plant configuration can be used by the spider to determine a (radial) direction in the plane perpendicular to the route of pursuit (Fig. 9, Table 2).

7. The jumping spider must employ at least two independent reference systems (route direction, gravity, visual cues) in concert to determine the position of the prey in space (Fig. 10 and Table 3, Fig. 11).

8. Apart from the context of predatory pursuit, the indirect pursuit of visually determined objectives is a general feature of the movement of salticid spiders upon vegetation. 


\section{Introduction}

Salticid spiders employ their highly developed vision in the detection, evaluation, and pursuit of potential prey. Since most of these spiders dwell on plants, where the most direct approach to sighted prey is seldom in the form of a straight line, effective access to that prey requires an ability to utilize an indirect route of pursuit.

Heil (1936) was the first to appreciate the significance of such detoured routes, in his study of the salticids Evarcha marcgravi and E. blancardi [currently E. arcuata (Clerck) and E. falcata (Clerck), respectively]. Unfortunately, Heil's observations of the 'höhere Leistungen', or attainments, of the salticid spider have received little attention in the subsequent literature. According to Curio (1976), "Salticid spiders have been credited with 'long detours' (Chrome, 1957). In view of its uniqueness in invertebrates a closer study of salticid hunting behavior appears highly desirable."

A salticid requires an accurate memory of the relative position of prey in space if it is to utilize a detour of any complexity. The objectives of this study include the evaluation of the ability of certain salticid spiders (Phidippus) to determine and successfully negotiate detours during the pursuit of prey, and the assessment of the forms of sensory information which can contribute to a memory of prey position during the course of such a detour.

\section{Materials and Methods}

The principal subjects of this study were individual Phidippus pulcherrimus Keyserling, collected as immatures from resting sacs on the herb Euthamia minor in Marion County, Florida. Predatory pursuits of P.audax (Hentz), P.clarus Keyserling, P.princeps (Peckham), and P.regius C.L. Koch were also observed.

All spiders were reared individually in plastic Petri dishes, provided with droplets of drinking water several times a week. Only adult spiders were used in the experiments reported here. As noted by Kästner (1950) in his study of Evarcha falcata, individual salticids can have distinct and consistent 'personalities', or individual modes of behavior as observed in a particular context. Management of spiders for the purposes of this study was therefore on an individual basis, as some individuals were markedly better performers in a given experimental situation than were others. Selection of individuals was based solely upon whether or not the spiders would repeatedly pursue a standard lure in each laboratory situation. Virtually all Phidippus observed during the course of this study (including rejects) demonstrated an ability to run a detoured pursuit, nonetheless. After screening, some attention was necessarily devoted to the care of 'runners', to maintain their responsiveness at a healthy optimum. A certain degree of food deprivation was required for this purpose; a spider subject to a current experiment was fed with flies (either Musca domestica or vestigial-winged Drosophila melanogaster) only when its opisthosoma was markedly reduced in size, a sign of starvation.

The basic technique employed in the laboratory study of the pursuit behavior and orientation of these spiders was simple. Individual spiders were placed upon structures of varying design, stimulated with a dead fly (Musca domestica) cemented to the end of a long, thin strand of hair (the standard lure; Fig. 11A), and then certain aspects of the ensuing pursuit and reorientation (see Fig. 1) were recorded in a manner which varied with the design of each experiment. For the study of orientation, a series of problems were designed to isolate each potential source of directional information (route direction, gravity, and background visual cues) in turn. Details of each experiment are presented, with the respective results, below. Most experiments involved a direct visual 
determination of the direction faced by the spider, by projection of the sagittal plane of the prosoma onto a visible scale. This process was greatly facilitated by the relatively large size $(9-18 \mathrm{~mm}$ in length) of Phidippus jumping spiders, the presence of conspicuous and symmetrical groups of lightcolored scales upon the prosoma of $P$. pulcherrimus and $P$. regius, and the tendency of these spiders to remain in a reoriented position for several seconds, if not longer, a fact which allows the observer to check the accuracy of his alignment from several angles. Where accurate determination of this direction was critical, the supporting rod of the standard lure (Fig. 11 A) was aligned with the sagittal plane of the spider (above positions 3 and 4 in Fig. 3C and E) and projected to the scale. As a test of the accuracy of this method, subsequent presentation of the prey in the estimated direction (position 4 in Fig. 3C and E) invariably failed to elicit an orienting turn (see Land, 1971) of appreciable magnitude; this suggests that the individual determination was within $5-10^{\circ}$ of the actual direction. Given the number of trials employed in each instance, it is likely that this error had a negligible effect upon the results.

Experimental structures were constructed with wood dowels of $4 \mathrm{~mm}$ and $9 \mathrm{~mm}$ diameter, heavy white paper, and corrugated cardboard. Unless otherwise specified, artificial lighting was provided by either a $100-\mathrm{W}$ or a $150-\mathrm{W}(1500-2500 \mathrm{~lm})$ incandescent light bulb, situated within an aluminum parabolic reflecting lamp at a distance of $0.5-1.5 \mathrm{~m}$ directly above each experimental situation.

Standard methods were employed in the statistical analysis of results (Runyon and Haber, 1971; Mendenhall and Scheaffer, 1973); for presumed parameters, means are presented here \pm 1 standard error.

\section{Results}

\section{Use of a Detour in the Pursuit of Prey}

Many species of Phidippus tend to occupy waiting positions near the top of herbacious plants, such as Solidago, in an open field. From such reconnaissance positions these spiders embark in pursuit of sighted prey. Indirect routes, or detours, provide the only access to most of the area subject to visual survey by the waiting spider; the facile use of such indirect routes of access can be readily demonstrated (Fig. 1).

Successful completion of the detoured approach requires not only an ability to select an appropriate detour with respect to the position of the prey, but also a memory of that position in space, if the prey is to be relocated by the spider. The pursuing Phidippus often stops and turns to face the expected position of its prey; this distinctive behavior is termed reorientation (to the prey position), and it provides a clear demonstration of the ability of these spiders to remember the position of their prey during pursuit. A single pursuit sequence may involve a series of reorientations from various positions as the spider approaches its prey. Each reorientation to face the primary objective of the pursuit (the prey position) can be viewed as the beginning of a subsequent segment of that pursuit.

\section{Selection of the Access Route}

In a series of experiments similar to that described in Fig. 2 (results in Table 1), the immediate direction of pursuit was determined by the relative position of a visible 'plant' configuration which completed the route of access. The method of alternate presentation of either variant ( $\mathrm{B}$ or $\mathrm{C}$ ) of this problem, thereby 

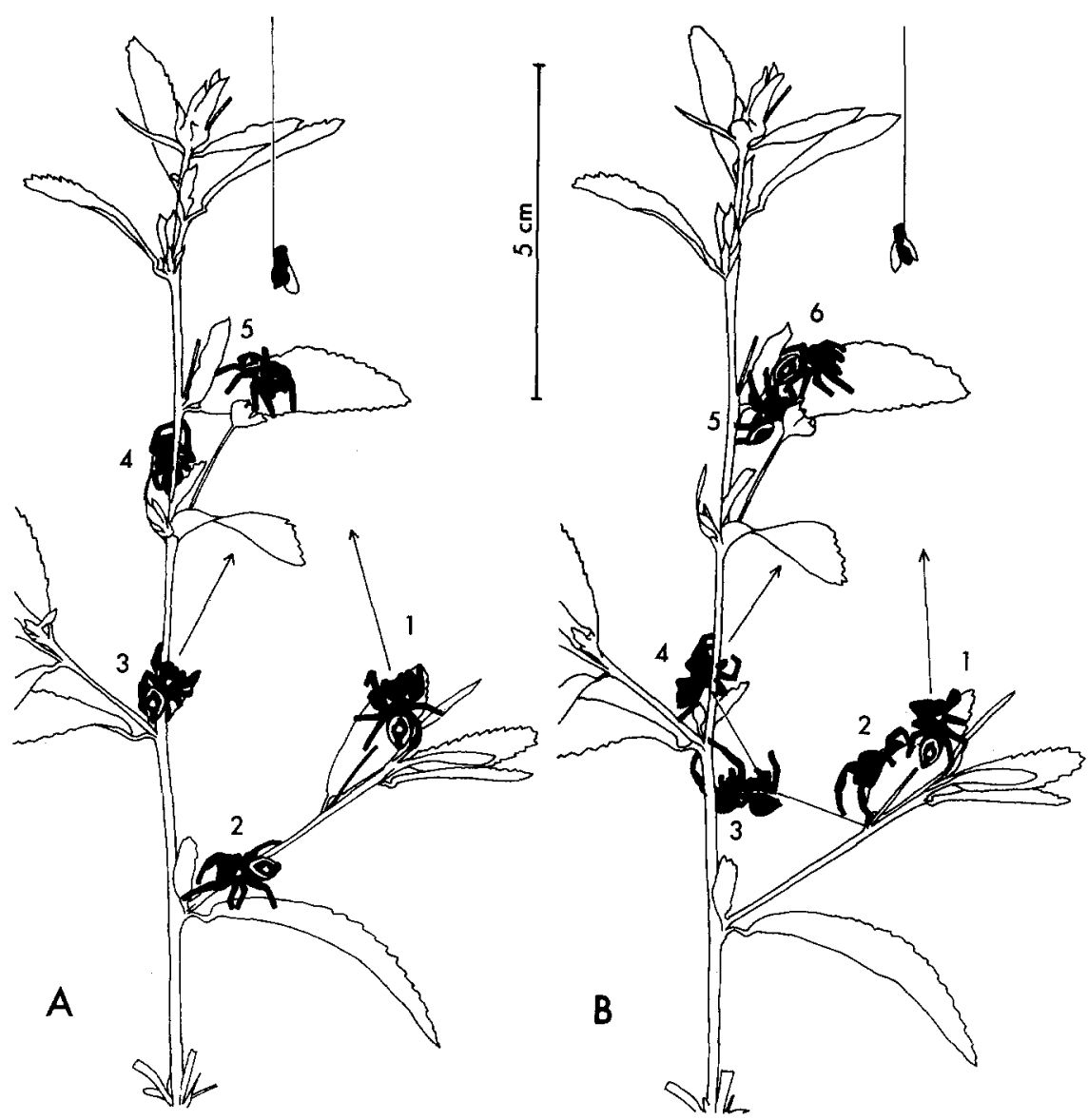

Fig. 1A and B. Two sequences of indirect pursuit of a standard lure (hanging fly) by a male $P$. pulcherrimus. Sequential (numbered) positions during the pursuit were traced from projections of a series of individual photographs taken with electronic flash. In each case the lure was removed immediately after the initial orientation to the prey (1). A The spider oriented to the prey position (1), turned and walked to the stem of the plant (2), and then reoriented to face the expected position of the prey from a new position (3). Subsequently the spider continued its ascent (4) to attain the objective position (5). B After orientation to the prey (1), the spider reached for an available dragline (2) which it climbed to the stem (3), and then reoriented to face the objective (4). Again, pursuit continued (5) until the spider attained the objective position (6)

requiring either a right or a left turn, suggests that familiarity with the problem cannot account for the observed results. In similar situations where a route of access was not readily visible, the spiders generally conducted an extensive series of turns, presumably in search of such a route. Visual orientation toward a route of access, prior to pursuit of that route of access, is readily demonstrated in a novel situation. A sighted plant configuration which replaces the primary objective (prey position) as a determinant of immediate behavior is termed a secondary objective. 


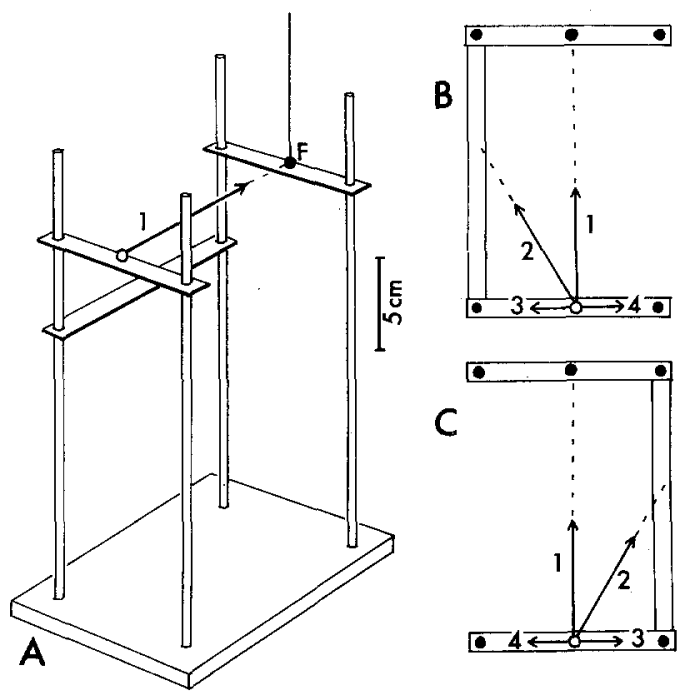

Fig. 2A-C. Problem of access requiring the use of a connection which is removed from the plane defined by the immediate route and the prey position. This problem is shown in perspective (A), and also in the two possible mirror-image configurations ( $B$ and $\mathbf{C}$ ) as viewed from above. $\mathbf{A}$ The apparatus is constructed of four vertical wood dowels connected by horizontal strips of heavy green paper. Each trial begins with the orientation (1) of the spider (open circle) to the fly $(F)$, as shown here. B, C After the initial orientation (1), the occurrence of a distinct turn to face the connecting route prior to movement from the starting position (2), and the direction of movement (either toward the route of access, 3 , or away from that route, 4 ) were recorded for each trial. Since data obtained for each of the two possible configurations (B and $\mathbf{C}$ ) were comparable for each spider, these data are pooled in Table 1

Table 1. Results for the problem of access described in Fig. 2

\begin{tabular}{llllll}
\hline $\begin{array}{l}\text { Spider } \\
\text { (individuals) }\end{array}$ & $\begin{array}{l}\text { Number of } \\
\text { trials }(N)\end{array}$ & $\begin{array}{l}\text { 2. Distinct } \\
\text { turn to face } \\
\text { access }\end{array}$ & $\begin{array}{l}\text { 3. Run } \\
\text { toward } \\
\text { access }\left(N_{3}\right)\end{array}$ & $\begin{array}{l}\text { 4. Run } \\
\text { away from } \\
\text { access }\left(N_{4}\right)\end{array}$ & $\begin{array}{l}P\left[N_{3}=N_{4},\right. \\
\text { with } \\
\text { chance }]\end{array}$ \\
\hline Female $P$. pulcherrimus & 41 & 41 & 41 & 0 & $<0.001$ \\
Female $P$. pulcherrimus & 40 & 40 & 40 & 0 & $<0.001$ \\
Female P. regitus & 38 & 30 & 34 & 4 & $<0.001$ \\
Male P. regius & 40 & 34 & 35 & 5 & $<0.001$ \\
\hline
\end{tabular}

The numbered column headings correspond to the events described in Fig. 2. Each spider had not only a highly significant tendency to move in the direction specified by the visible route of access, but also a tendency to face that access directly prior to pursuit (2). The two female $P$. pulcherrimus repeatedly ran the problem in either direction like clockwork, never missing a distinct turn to face the access route prior to pursuit

In a substantial majority of the access problems presented to various Phidippus during the course of this study, the spiders utilized the most direct route of access to prey that was available. One might think that a considerable amount of insight on the part of the spider was required to achieve this particular result, but it is easier to explain this efficiency with a simple 
evaluation of the constraints placed upon the spider's choice of a direction of movement upon the plant. A stem, for example, allows for only two directions of movement. The spiders consistently selected the direction of movement which brought them closer to an immediate objective. Thus the ability of Phidippus to solve a complicated problem of access depends upon its ability to substitute intervening (secondary) objectives for the primary objective, as determinants of immediate behavior.

Each segment of a pursuit sequence may involve the setting of a new secondary objective after reorientation to the primary objective. Thus a series of intervening, immediate objectives may be employed during the course of a single pursuit.

\section{Orientation with Reference to the Direction of Pursuit}

Memory of a relative position in space, as expressed in the reorientation of the pursuing Phidippus to face its prey, requires the use of reference directions. Of all the potential references which might be employed by the spider to determine a direction in space, the orientation of the body axis itself is most immediate. As salticids orient toward sighted prey in the absence of visual feedback (Land, 1971; Duelli, 1978), they are in effect utilizing the orientation of the prosoma in space (corresponding to the position of the eyes) as a reference direction for the execution of an appropriate directed turn. In a broader sense, the immediate route of the spider can also provide a very useful reference direction during its pursuit of prey. Angles which specify a direction with reference to the direction of pursuit are denoted as $\theta$; orientation of these animals with reference to the direction of the immediate route is termed route-referent orientation.

The apparatus and terminology used to analyze the route-referent orientation of Phidippus during a segment of pursuit along a horizontal route are shown in Fig. 3. Representative results of this experiment are presented in Fig. 4A. For each trial, involving the presentation of the prey at a variable direction with reference to the horizontal bar (variable orientation angle, $\theta$ ), the measured angle of reorientation $\left(\theta_{r}\right)$ is presented here as a function of both $\theta$ and $\theta_{c}$, as defined in Fig. 3B. After each initial orientation to the prey, the prey was concealed from the view of the pursuing spider, and thus it could not serve as a visual reference to direct the subsequent reorientation. From the results shown here, which agree with those obtained with a number of individual P.clarus, $P$. princeps, and $P$. pulcherrimus, it is possible to draw several conclusions. First, for each of the spiders, the actual reorientation angle $\left(\theta_{r}\right)$ correlated quite significantly with, and approximated somewhat, the initial orientation angle $(\theta)$.

In addition, $\theta_{r}$ was significantly greater than $\theta$ in magnitude, in general. This is demonstrated by the fact that, for each spider, $\overline{\theta_{r}-\theta}$ is significantly $(P<0.0001)$ greater than 0 . The graphic presentation of $\theta_{r}$ as a function of $\theta$ provides a clear exhibition of this result. From an examination of Fig. $3 \mathrm{~B}$, one can see that the expected value of $\theta_{r}$, if it were compensated for the movement of the spider relative to the prey position, should exceed the value of $\theta$. As the spider approaches its prey, the reorientation angle required to face that prey 


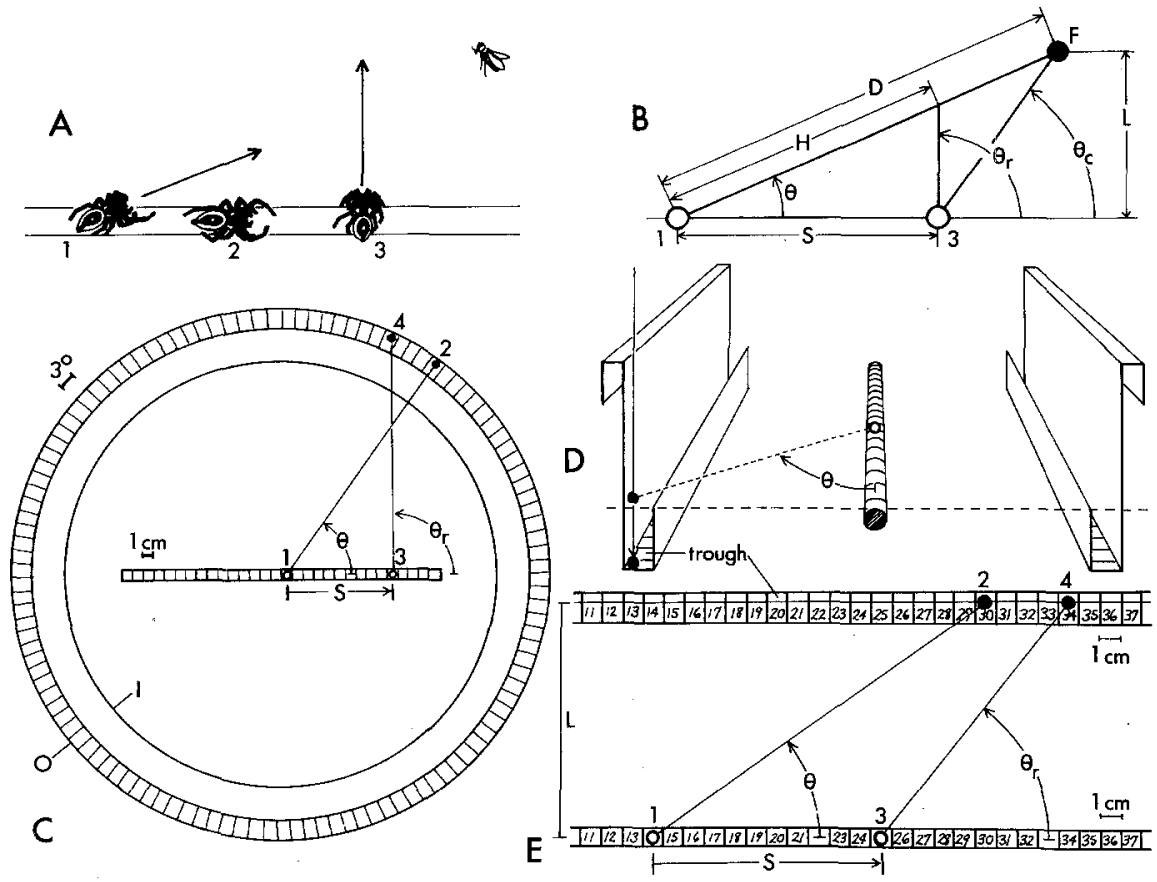

Fig. 3. A A simple segment of linear pursuit in a horizontal plane, as viewed from above. The spider faces the prey (1), which is immediately removed from view as the spider turns to run in pursuit (2), and then stops to reorient (3). B Definition of terminology used to describe the pursuit shown in (A). C Circular arena used for the observation of orientation by the spider during pursuit on the horizontal bar, as viewed from above. The inner white paper cylinder $(l)$ rises to the level of the top of the running bar, while the outer cylinder $(0)$ extends to a height of $30 \mathrm{~cm}$ above the bar. Prior to each trial, the spider was led back to a center position (1) on the horizontal bar with a standard lure, to maintain a constant prey distance of about $25 \mathrm{~cm}$ at the initial sighting. To initiate each trial, the prey was presented to the spider in a circumferential position (2). Subsequently, as the prey was dropped below the view of the spider (between the two cylinders), the spider ran to a new position (3) on the horizontal bar and reoriented in the direction of position (4) on the circumferential scale. From a record of values 1-4, the descriptive terms defined in (B) could be calculated for each trial. D Perspective view of horizontal bar in corridor, showing how the suspended fly could be concealed in the trough during the pursuit and reorientation of the spider. E Horizontal bar in corridor viewed from above. As in (C), a record of positions 1-4 was made for each trial. The prey distance for a given $\theta$ could be varied by changing the distance $(L)$ between the bar and the peripheral (fly position) scale

directly $\left(\theta_{c}\right)$ increases. As shown here (Fig. $\left.4 \mathrm{~A}\right), \theta_{c}$ was an effective predictor of the observed reorientation angle $\left(\theta_{r}\right)$.

A more rigorous demonstration of the role of the immediate route (or direction of pursuit) as a reference direction, to the exclusion of peripheral visual cues, is provided by the ability of Phidippus to complete a segment of pursuit, followed by an accurate reorientation (with $\theta_{c}$ as a predictor of $\theta_{r}$ ), in complete darkness (Fig. 4B).

It is evident that each reorientation represents an attempt by the spider to face the expected position of its prey. Based upon definitions provided in Fig. $3 \mathrm{~B}$, one can conclude that $\theta_{c}$ (the optimal reorientation angle) is a function 

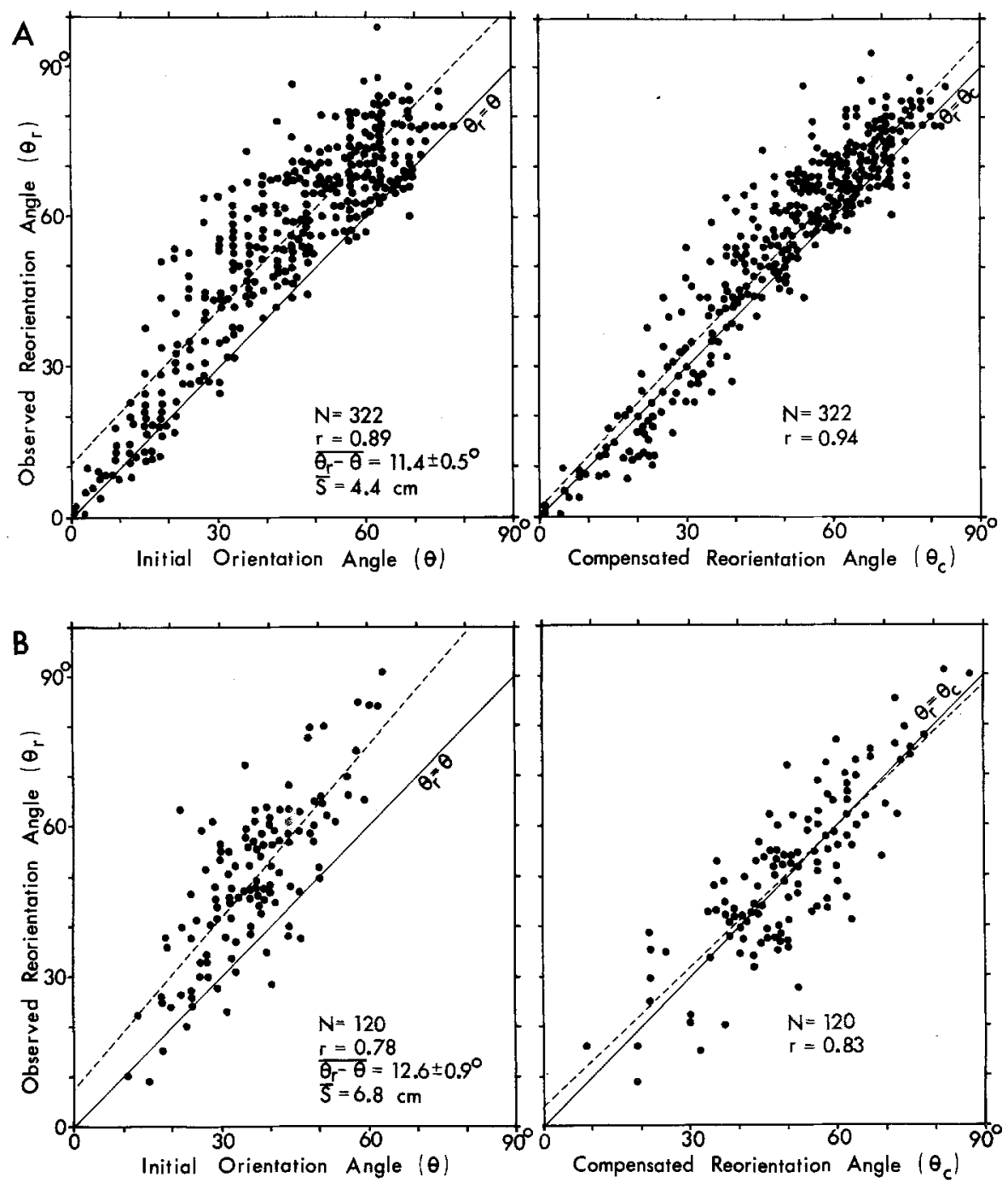

Fig. 4. A Behavior of a female $P$. pulcherrimus on the horizontal bar (Fig. $3 \mathrm{C}$ ), in response to a variable direction of prey presentation (variable $\theta$ ). Here the measured angle of reorientation with reference to the direction of pursuit $\left(\theta_{\mu}\right)$ is presented as a function of both the initial orientation angle $(\theta)$ and the calculated (movement compensated) reorientation angle required to bring the spider to face the original prey position directly $\left(\theta_{c}\right)$. As in subsequent figures, the linear regression of $\mathrm{Y}$ on $\mathrm{X}$ is indicated as a dashed line. B Behavior of a different female $P$. pulcherrimus on the horizontal bar. As in (A), these data were obtained with the apparatus described in Fig. 3C. For these trials, however, the overhead light was switched off as soon as the spider turned to run in pursuit. Only those trials in which the reorientation turn had been executed completely prior to the time at which the light was subsequently turned on (several seconds later) are shown here. In one of these trials the spider was even preparing to jump in the prey direction as the light went on. In a number of trails, this spider did not reorient until after the light was switched on, and these trials were not recorded. In all respects these data compare with those collected under conditions of continuous illumination, as in (A). It should be noted that the spiders always reoriented to the correct side (whether right or left) of the bar 


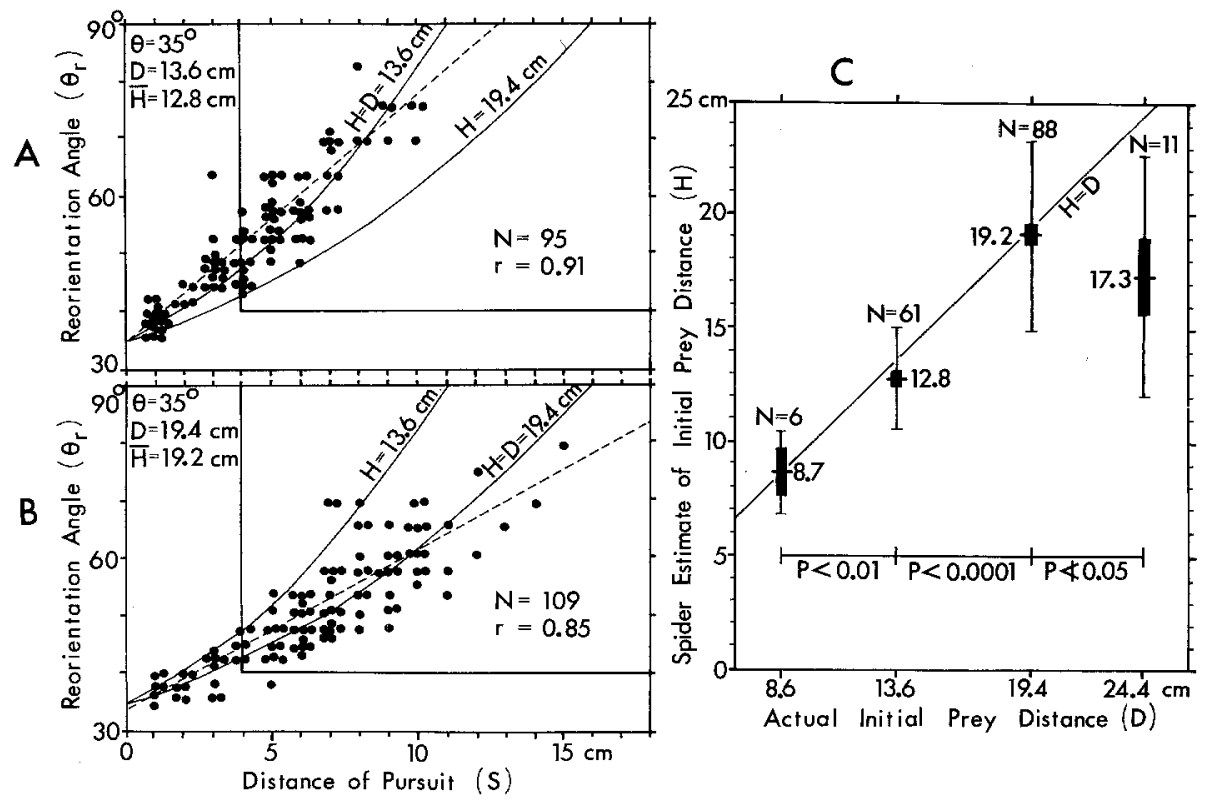

Fig. 5A-C. Behavior of a female $P$. pulcherrimus during a segment of pursuit upon the horizontal bar (Figs. 3D and $\mathrm{E}$ ) in response to a constant $\theta\left(=35^{\circ}\right)$, and a variable prey distance $(D)$. A Reorientation angle $\left(\theta_{r}\right)$ as a function of the pursuit distance $(S)$, for a constant $D=13.6 \mathrm{~cm}$. As demarcated by the inset rectangle, $H$ values used in the determination of $\bar{H}$ were calculated only for those trials in which $\theta_{r} \geqq 40^{\circ}$ and $S \geqq 4 \mathrm{~cm}$. B As in (A), but $D=19.4 \mathrm{~cm}$. C Comparison of the spider estimate of prey distance $(H)$ to the actual prey distance $(D)$. For each value of $D$, the mean $H$ is given \pm one standard error (thick vertical bar), with a vertical line indicating \pm one standard deviation of the range of calculated $H$ values. $P$ values given below indicate whether the respective values of $\bar{H}$ varied significantly with a change of $D$ for this spider

of $D$ (the initial distance of the prey), $\theta$ (the initial direction of that prey with reference to the route of pursuit), and $S$ (the distance of pursuit prior to reorientation):

$$
\theta_{c}=\tan ^{-1}\left[\frac{\sin \theta}{\cos \theta-(S / D)}\right] \text {. }
$$

By this analysis, the spider should be able to integrate three forms of information $(D, \theta$, and $S)$ to develop an accurate appraisal of the relative direction of the prey with reference to the direction of pursuit.

The fact that $\theta_{r}$ was significantly greater than $\theta$ could represent the use of a simple adaptive output by the spider, based upon a neurological analog to the generalization that $\theta_{c}$ is always greater than $\theta$ to some extent. This might provide a sufficiently accurate reorientation angle in most cases, independent of an ability to evaluate either $D$ or $S$. For this reason, the horizontal bar was employed within a corridor (Fig. 3D and E) with a constant $\theta\left(=35^{\circ}\right)$, to measure the role of $S$ as a determinant of $\theta_{r}$. As shown here (Fig. $5 \mathrm{~A}$ and $\mathrm{B}$ ), a highly significant positive correlation between $S$ and $\theta_{r}$, as predicted by the 

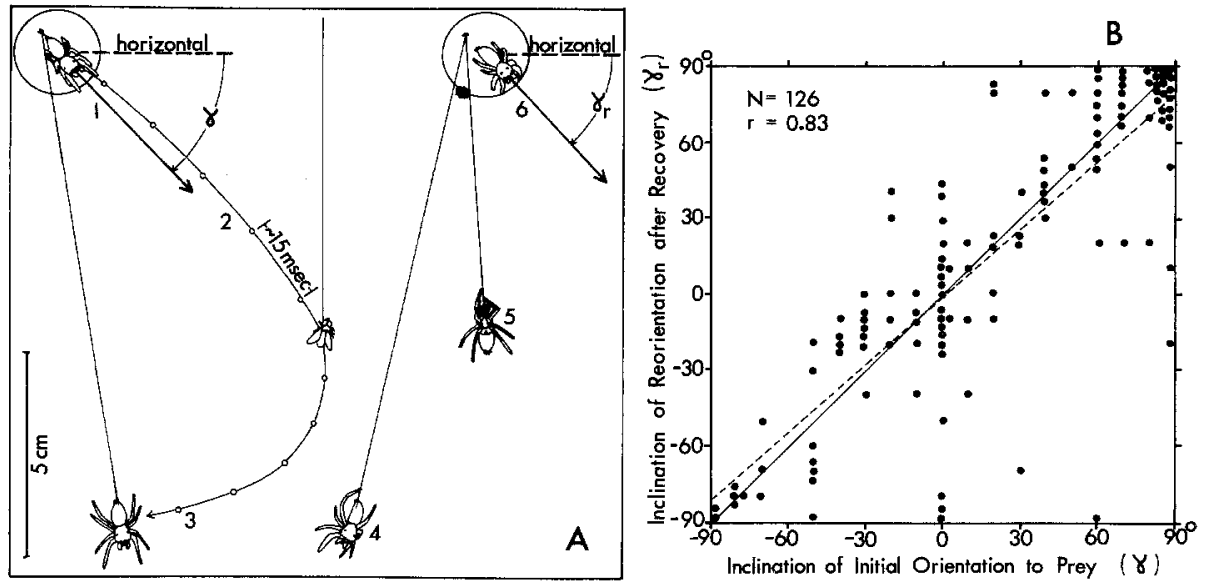

Fig. 6. A Description of the jump-recovery behavior of Phidippus. The spider waited upon a heavy paper disk at the end of the axial horizontal bar of the apparatus shown in Fig. $7 \mathrm{~A}$. Thus visual cues could not be used by the spider to determine a direction in the vertical plane defined by the paper disk (waiting platform). Orientations were recorded by using a circumferential scale like that shown in Fig. 7. Initially ( 1 ) the spider oriented toward the prey at a measured inclination ( $\gamma$ ). In successful trials, the spider jumped toward the prey (2), but missed the lure as it was quickly removed by the observer, careful to anticipate the jump of the spider. The spider would then swing as a pendulum (3), and then catch the dragline with a leg IV (4). After climbing the dragline with legs I and II (5) to recover to the jumping position, the spider discarded the wound dragline. The spider immediately reoriented (6) to the expected prey position at inclination $\gamma_{r}$. B Pooled jump-recovery data for 13 individual $P$. pulcherrimus. The agreement and correlation of $\gamma_{r}$ with $\gamma$ was highly significant. Pooling of data was required by the fact that, after missing a certain number of jumps, individuals would only jump when capture was certain, when the lure was so near to the spider that it could not be removed fast enough by the observer. Presumably only gravity was available as a reference for memory of prey direction in the plane of this experiment

equation given above, did in fact exist. In this experiment, variation in $S$ was an intrinsic feature of the behavior of individual Phidippus, when presented repeatedly with the same problem of access. It appears, then, that Phidippus can utilize a memory of the extent of their own movement $(S)$ during pursuit to determine an accurate approximation of $\theta_{c}$.

As shown in Fig. $5 \mathrm{~A}$ and B, each collection of correlated values of $S$ and $\theta_{r}$ can be approximated by a function based upon a fixed value for the "estimate of prey distance' by the spider, or $H$ as it is defined in Fig. 3B. By definition:

$$
H=\frac{S}{\cos \theta-\left(\sin \theta / \tan \theta_{r}\right)} .
$$

Since each trial produced measurements of $\theta, S$, and $\theta_{r}$, it was possible to calculate a value of $H$ for each trial. Analysis of these data (Fig. 5C) shows that, within limits, $D$ (actual prey distance) is a significant predictor of $\bar{H}$. The upper limit for accurate resolution of prey distance $(D$ as a predictor of the observed $H$ ) in this particular experiment ranged from 10 to $20 \mathrm{~cm}$ for different $P$. pulcherrimus. 


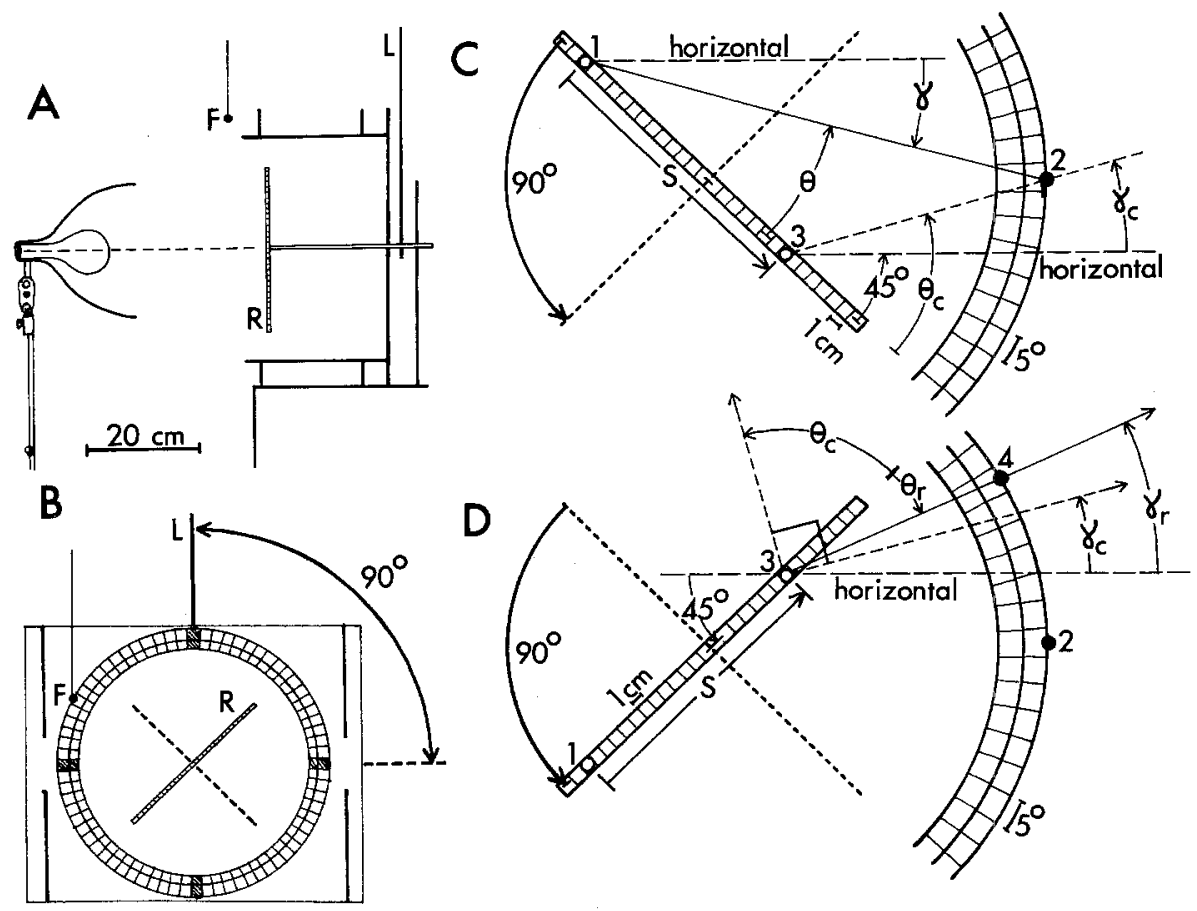

Fig. 7. A Axial section (in vertical plane) of the apparatus used for rotation of the running bar during a segment of pursuit. The lever $(L)$ used to rotate the running bar $(R)$ within a horizontal white paper cylinder was supported by a framework of corrugated cardboard. Careful alignment of the axis of the incandescent lamp (in an otherwise dark room) eliminated visual cues which might have been used by the spider to determine the direction of the fly position $(F)$ as measured on the circumferential scale shown in (B). B Front view (vertical plane projection) of this apparatus, indicating the coupled $90^{\circ}$ rotation of lever and running bar during pursuit. $\mathbf{C}$ Position of running bar upon initiation of pursuit. The spider (position 1) initially turned to face the lure (2). As the spider turned to run toward position (3), the bar was rotated $90^{\circ}$ as shown here. Relevant terms for the description of this problem are defined in a manner consistent with that shown in Fig. 3B. D Position of the running bar (after rotation) as the spider reoriented. The $90^{\circ}$ rotation of the bar during pursuit moved the prey direction specified with reference to the direction of pursuit $\left(\theta_{c}\right)$ into conflict (by $90^{\circ}$ ) with the direction specified by the use of gravity, or inclination $\left(\gamma_{c}\right)$ information. As shown here (and in Fig. 8), the actual reorientation agreed with the direction specified by $\gamma_{c}$. As in earlier experiments, a record of positions $1-4$ provided a complete description of the orientation of the spider during this segment of pursuit

\section{Orientation with Reference to Gravity}

Gravity is always available as a reference direction for the spider. As a convention here, directions with reference to gravity are specified by their inclination $(\gamma)$, when $\gamma$ is the angle between the specified direction and its projection upon a horizontal plane. Directions above the horizontal plane are assigned positive $\gamma$ values; those below the horizontal plane have negative $\gamma$ values. Therefore $\gamma$ varies from a maximum of $+90^{\circ}$ (straight up) to a minimum of $-90^{\circ}$ (straight down). 


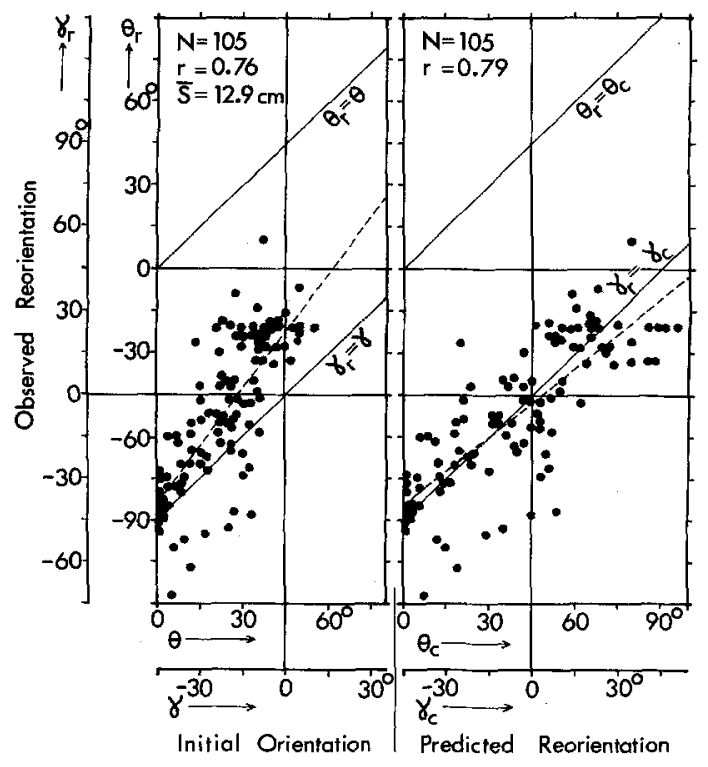

Fig. 8. Results of the rotation experiment described in Fig. 7 for a male P. pulcherrimus. This experiment worked much better with this particular individual than with others (although with the same result), due to the tendency of this spider to run long and fast pursuits $(\bar{S}=12.9 \mathrm{~cm})$. Each long pursuit allowed ample time for the smooth rotation of the bar prior to reorientation. Here the observed direction of reorientation (either $\gamma_{r}$ or $\theta_{r}$ ) is presented as a function of both the initial direction of orientation ( $\gamma$ or $\theta$ ) and the predicted or movement-compensated direction of reorientation $\left(\gamma_{c}\right.$ or $\left.\theta_{c}\right)$, in a manner consistent with definitions presented in Fig. $7 \mathrm{C}$ and D

The ability of Phidippus to retain a memory of the direction of sighted prey with reference to gravity (gravity-referent orientation) is demonstrated by the jump-recovery experiment (Fig. 6).

The apparatus described in Fig. 7 was used to determine the ability of Phidippus to reorient to a prey position when both the prey and the route of access were situated in the same vertical plane. Regardless of the orientation of the route of access, accuracy of reorientation compared with that described for pursuit in a horizontal plane (Fig. 4). Since this could be the result of either route-referent or gravity-referent orientation by the spider, the problem described in Fig. 7, involving rotation of the bar in a vertical plane during pursuit, was devised to place the two forms of information into conflict. As a result (Fig. 8), the direction of reorientation agreed with the use of gravity as the preferred reference system in this situation $\left(\gamma_{c}\right.$ was an effective predictor of the observed $\gamma_{r}$ ). In contrast to this result, Phidippus continued to rely upon routereferent information, to the exclusion of conflicting visual cues, when a similar experiment was conducted in a horizontal plane.

\section{Orientation with Reference to Visual Cues}

Directions which might be specified visually during a pursuit can, as a convention, be separated into two independent components: an angle with reference 

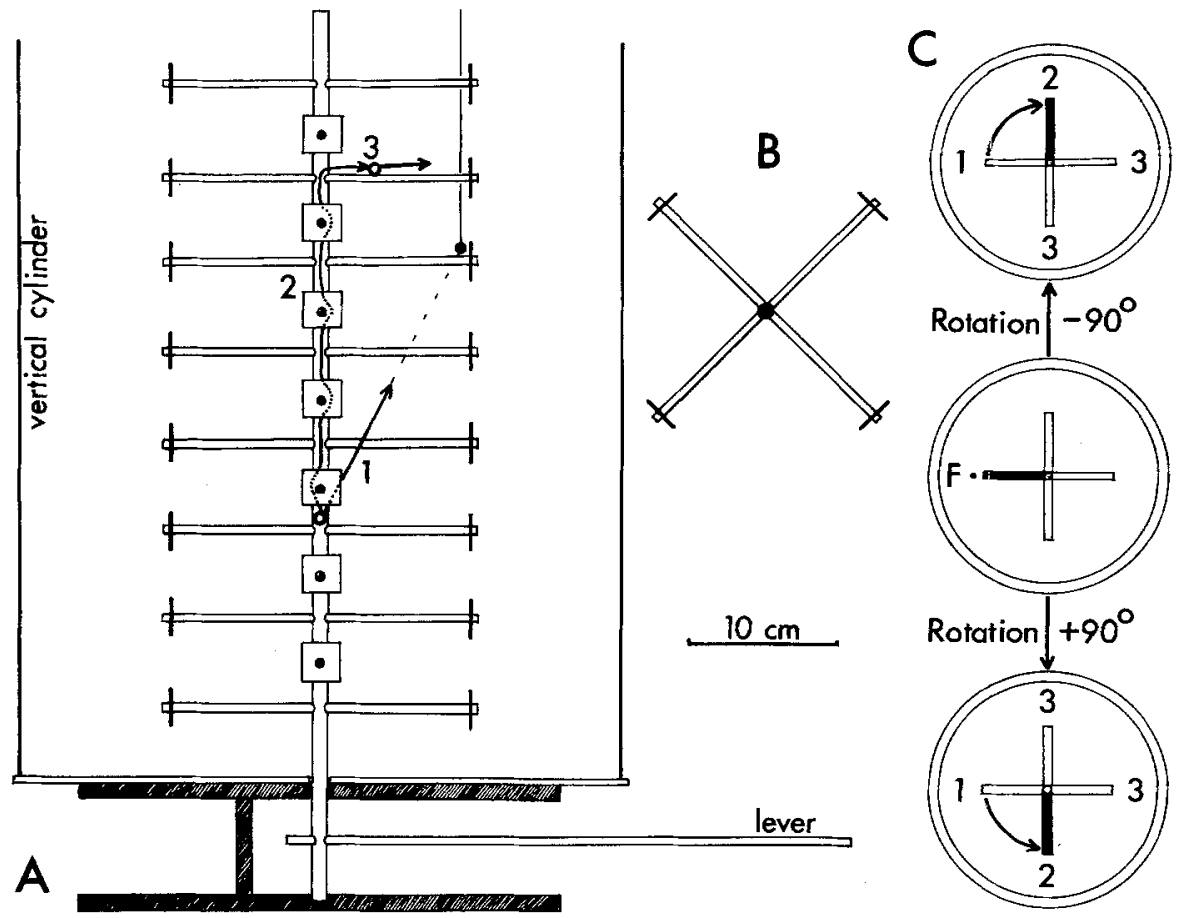

Fig. 9A-C. The rotating plant experiment. A Vertical plane projection of the apparatus. The removable vertical cylinder which surrounds the plant is constructed of heavy white paper. The plant itself consists of a series of horizontal wood dowels (branches) passing through a thicker stem. The lever shown here was used to rotate the plant by $90^{\circ}$ during pursuit. In each trial, the spider first (1) turned to face the standard lure in one of four radial directions corresponding to the direction of the branches as viewed from above (B). The spider then ran a necessarily winding pursuit up the stem (2), to reorient (3) in one of the four radial directions. As shown here, each trial began with the spider on the stem at least two rungs $(12 \mathrm{~cm})$ below the position of the prey. Upon initiation of pursuit, the prey was immediately removed, and rotation of the plant was completed before reorientation. B Horizontal plane projection of this plant. C Schematic views of this apparatus from above. At center, the initial position of the fly $(F)$ prior to rotation of the plant is indicated. Whether the rotation of the plant during pursuit was $+90^{\circ}$ or $-90^{\circ}$, the resultant reorientation could be classified in one of three ways. The spider reoriented to face either the original direction of its prey in space (1), the direction of the branch (rotated by $90^{\circ}$ ) where that prey originally appeared ( 2 ; here that branch is marked in black although it is not so marked in the experiment), or some other direction (3)

to the direction of movement $(\theta)$, and a radial direction which is perpendicular to that direction of movement (termed a radial orientation). In the determination of a radial ( $\theta$-independent) orientation, visual cues beyond those provided by the immediate route can be of some use. Since the combination of prey position (a point) and the route itself (a line) can specify a unique plane in space, the prey position always remains in the same radial orientation with respect to a linear route. Thus no compensation for movement is required to determine the radial orientation of the prey from a new position along a linear route.

Only when the spider is required to determine a radial direction from a completely vertical route of access, is the radial orientation completely inde- 
Table 2. Pooled results of the rotating plant experiment (Fig. 9) for four adult P. pulcherrimus

\begin{tabular}{|c|c|c|c|c|c|}
\hline \multirow[t]{2}{*}{ Series } & \multirow[t]{2}{*}{$\begin{array}{l}\text { Condition of } \\
\text { visual surround }\end{array}$} & \multirow[t]{2}{*}{$\begin{array}{l}\text { Number of } \\
\text { trials }(\mathrm{N})\end{array}$} & \multicolumn{3}{|c|}{$\begin{array}{l}\text { Reorientations to face } \\
\text { the prey direction }\end{array}$} \\
\hline & & & $\begin{array}{l}\text { 1. in } \\
\text { space }\end{array}$ & $\begin{array}{l}\text { 2. on the } \\
\text { plant }\end{array}$ & 3. other \\
\hline A & $\begin{array}{l}\text { white cylinder, lamp } \\
\text { centered above plant }\end{array}$ & 210 & 10 & 177 & 23 \\
\hline B & $\begin{array}{l}\text { open room (no cylinder) } \\
\text { lamp centered above plant }\end{array}$ & 202 & 87 & 110 & 5 \\
\hline C & $\begin{array}{l}\text { no cylinder, sunlight, } \\
\text { under a blue sky }\end{array}$ & 112 & 88 & 22 & 2 \\
\hline $\mathrm{D}$ & $\begin{array}{l}\text { white cylinder, clear } \\
\text { blue sky at zenith }\end{array}$ & 163 & 9 & 134 & 20 \\
\hline
\end{tabular}

The numbered column headings correspond to the classification of results given in Fig. 9C. Enumerated results for series $\mathrm{B}$ and $\mathrm{C}$ were significantly different from those of control series $\mathrm{A}$ $(P<0.001$ in each case). This significant increase in type ( $l)$ results can be attributed to the use of either background visual cues by the spider (series B), or to the use of a combination of background cues with cues provided by shadows on the immediate plant (the latter possibility has not been ruled out with the more natural conditions allowed in series $C$ ). Results for series $D$ were virtually identical with those for the control series $\mathrm{A}$

pendent of both route-referent and gravity-referent orientation. For this reason the experiment described in Fig. 9 was designed to pose the problem of radial orientation after a vertical segment of pursuit. As shown here, the configuration of this artificial plant was radially symmetrical in horizontal projection, allowing the spider, which in general reoriented toward one of the branches associated with the prey, a choice of four radial directions in the context of a certain amount of visual ambiguity. This ambiguity (identical branches facing in each direction from the stem) was necessary to avoid the generalized recognition of a branch associated with the prey by its form, as the sole determinant of radial orientation.

Results of this rotation experiment are presented in Table 2. When the plant was rotated within a uniform, closed cylinder (series A), each spider maintained an accurate radial orientation with reference to cues provided by the plant itself, regardless of the fact that a pursuit often involved an ascent of more than $30 \mathrm{~cm}$ prior to reorientation. The course of each ascent necessarily wound around the stem to avoid the obstacles posed by the attachment of branches. When the surrounding white cylinder was removed (series $B$ and $C$ ), the $90^{\circ}$ rotation of the plant during pursuit produced a conflict between the use of background visual cues and those cues provided by the experience of the spider upon the plant. With these cues in conflict, the spiders followed background cues in a significant fraction of the trials.

Data from a related experiment designed as a potential demonstration of the use of the pattern of polarized skylight at the zenith to determine a radial orientation are also presented here (Table 2, series D). Phidippus continued to 


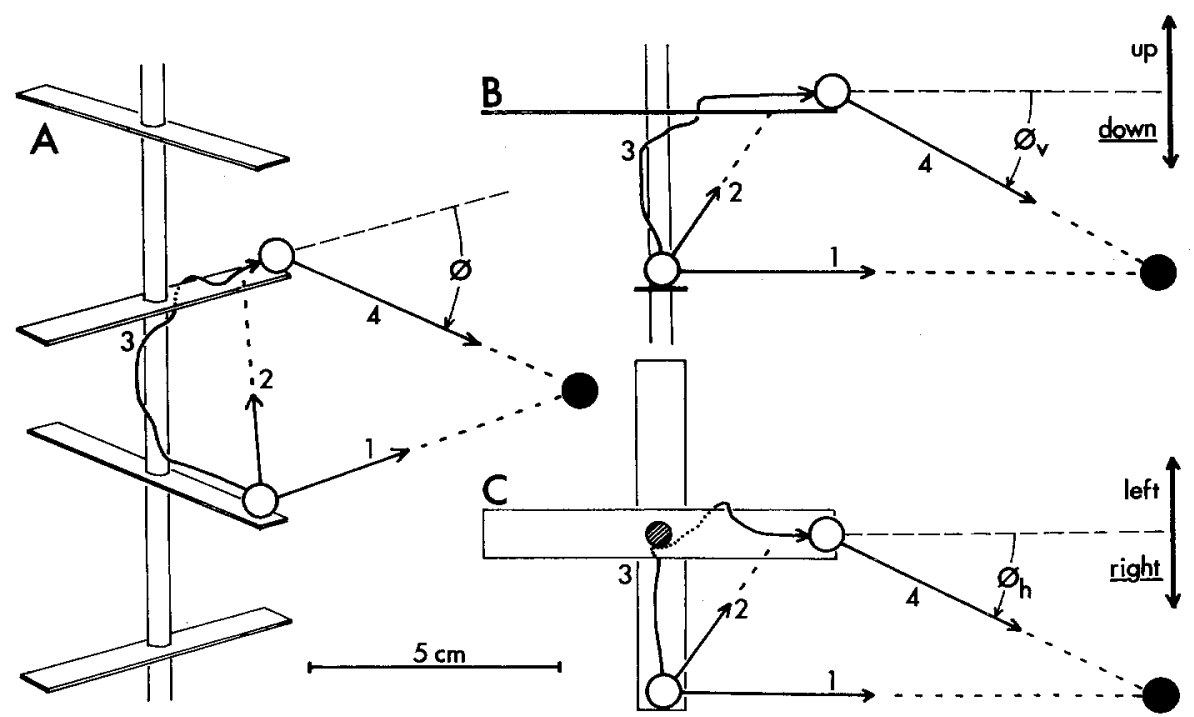

Fig. 10. A Perspective drawing of an apparatus used to examine the ability of Phidippus to compensate for movement in three dimensions in the determination of a prey direction from a new position. The plant (consisting of a vertical wood dowel and horizontal leaves of heavy green paper) was situated within a partial white cylinder like that shown in Fig. 11 A. After the initial orientation to face the prey in a horizontal plane (1), the prey was immediately removed in each trial. Many spiders turned to face the secondary objective as shown here (2), and then moved to that secondary objective (3) prior to reorientation (4). In this situation, a reorientation turn (magnitude $\phi$ ) which compensates for the movement should be both down and to the right. B Vertical plane projection of this problem. The component of reorientation in a vertical plane $\left(\phi_{v}\right)$ should be directed distinctly downward, to compensate for movement by the spider to a position above its prey. $\mathbf{C}$ Horizontal plane projection of the same pursuit. The horizontal component of reorientation $\left(\phi_{h}\right)$ should be distinctly to the right, as shown, to compensate for movement. Not all individuals would readily run this indirect pursuit, but for those which did so the direction of reorientation was recorded for each trial as either distinctly compensated or not with respect to each component $\left(\phi_{v}\right.$ and $\left.\phi_{h}\right)$. In half of the trials shown in Table 3 , the mirror image of the problem figured here was employed, requiring a distinct turn to the left for a compensated $\phi_{h}$

orient with reference to their experience upon the immediate plant configuration, as if the information available in the pattern of sky polarization did not exist. In this experiment, the spider initially sighted the prey as a silhouette against a background of blue sky at the zenith (with a low solar altitude) at the onset of each trial. At present there is no evidence to indicate that Phidippus can utilize polarized light patterns to determine a radial orientation.

\section{Compensation for Movement in Three Dimensions}

Figure 10 and Table 3 provide a demonstration of the ability of Phidippus to reorient accurately after a segment of pursuit which is not confined to a single plane. 
Table 3. Pooled results of the experiment described in Fig. 10, for eight $P$. pulcherrimus

\begin{tabular}{lc}
\hline Result & $\begin{array}{l}\text { Number of } \\
\text { trials }(N)\end{array}$ \\
\hline 1. Both horizontal and vertical components of reorientation & \\
$\left(\phi_{h}\right.$ and $\left.\phi_{v}\right)$ are compensated for movement & 158 \\
2. Only the horizontal component $\left(\phi_{h}\right)$ is compensated & 18 \\
3. Only the vertical component $\left(\phi_{v}\right)$ is compensated & 20 \\
4. Neither component is compensated & 2 \\
[Total number of trials] & 198 \\
\hline
\end{tabular}

Directional components were considered to be compensated only if this occurred in the absence of any ambiguity whatsoever. For the variant of this problem shown in Fig. 10, this corresponds to a reorientation down (for a compensated $\phi_{v}$ ) and to the right (for a compensated $\phi_{h}$ ). Intermediate (hence ambiguous) orientations were not considered to be compensated for movement. Compensation of either $\phi_{h}$ (results 1 and 2) or $\phi_{v}$ (1 and 3) was observed in a highly significant $(P<0.0001$ in each case $)$ majority of the trials

\section{Discussion}

\section{Orientation in Three Dimensions}

Short-term memory of the prey position has been demonstrated in the context of each of three independent reference systems .(direction of pursuit, gravity, and visual cues which specify a radial direction), by the isolation of each system in turn. Nonetheless, even in the preceding experiments, Phidippus demonstrated an ability to orient in three-dimensional space. The ability to specify a relative position in space requires the use of at least two independent reference directions (they need not be perpendicular) to specify direction, in addition to an appraisal of distance. As an example, the horizontal bar (Fig. 3) can be used for the study of route-referent orientation in the horizontal plane, but only because gravityreferent and radial (visual) information both define that same horizontal plane. There is no doubt that Phidippus can reorient successfully in space, employing at least two independent reference systems in concert for the specification of a direction. Since only two reference directions are required to define a direction in space, the use of at least three systems by these spiders demands some explanation.

By definition, the route-referent and the radial orientations of the prey position are always independent; thus the two always suffice to determine a unique direction in space. Both references may be required in certain situations. Granted that gravity-referent information is always available, an additional gravity-independent reference is also required. In this regard, route-referent information becomes more important as the route approaches the horizontal. Similarly, radial orientation is required when the direction of pursuit is vertical.

An interesting feature of many segments of pursuit, like that described in Fig. 10, is the fact that the route of the spider may be alternately horizontal and then vertical during the run, prior to reorientation. Successful reorientation after 


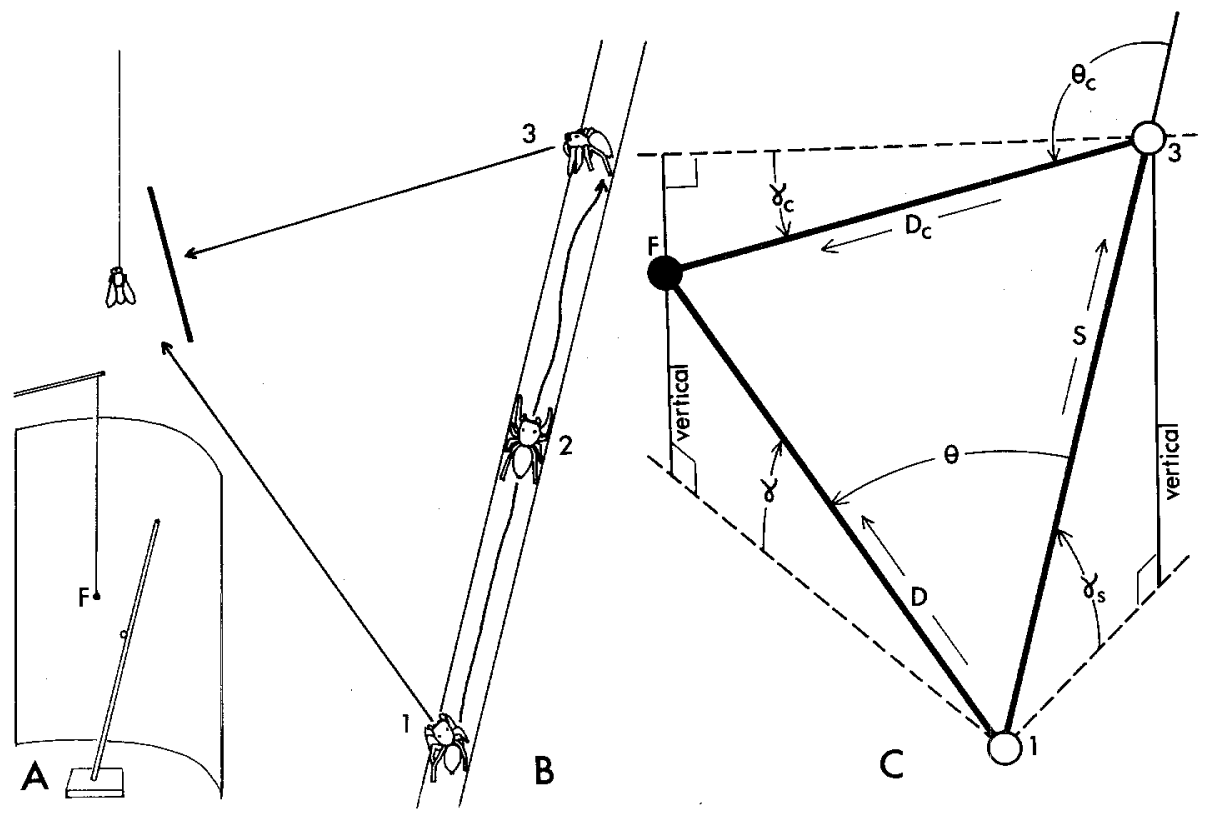

Fig. 11 A-C. Compensation for movement along an inclined (skewed) linear route of pursuit. A View of the simple apparatus that can be used for this demonstration. The fly $(F)$ is presented to the spider (open circle) which rests upon an inclined wood dowel within a partial white cylinder, used to limit the use of extraneous visual information by the spider. B Schematic view of a sequence of skewed linear pursuit. After orientation to the prey (1), the spider ascends the skewed route (2) as the prey is removed, then completes an accurate reorientation (3). $\mathbf{C}$ Terms used in the description of this segment of pursuit in three dimensions. New terms include the inclination of the route of pursuit $\left(\gamma_{s}\right)$ and the distance between the position of reorientation by the spider and the original prey position $\left(D_{c}\right)$. Other terms agree with definitions provided earlier

a pursuit of this sort should require the successive use of both route-referent and radial information at different times, to act in concert with the omnipresent gravity-referent information. This suggests that Phidippus can transpose information (with regard to prey direction) between the two gravity-independent systems during a single segment of pursuit. The relative stability of the gravityreferent information, irrespective of the problems (such as transposition) posed by the use of a curving pathway amid plant configurations of changing appearance, without doubt contributes greatly to the ease with which these spiders can maintain a memory of prey position. The apparent dominance of gravityreferent information over conflicting route-referent information (Fig. 8) has a counterpart in the experience of these spiders in nature, where gravity remains a useful reference even as supporting leaves or stems give way under the weight of the spider.

Two simple demonstrations of the ability of Phidippus to compensate for movement in three dimensions are given here (Fig. 10 and Table 3; Fig. 11). As noted above, radial orientation is only required if the route is completely vertical; in all other situations route-referent and gravity-referent information 
will suffice, given a certain handedness (which does exist) on the part of the spider. Since the visually determined radial direction remains constant during a linear segment of pursuit (Fig. 11), movement compensation is basically relevant to the use of route-referent and gravity-referent information.

In theory, compensation for movement in space is rather simple: The vector of movement during pursuit (magnitude $S$ ) must be subtracted from the initial spider-to-prey vector (magnitude $D$ ), to determine the new spider-to-prey vector (magnitude $D_{c}$ ). Figure $11 \mathrm{C}$ provides a description of the information content of this problem, with respect to the use of the spider-centered route-referent and gravity-referent systems. Based upon the relationships shown in Fig. 11C, the two directional components of reorientation can be calculated:

$$
\theta_{c}=\sin ^{-1}\left[\frac{D \sin \theta}{\left(D^{2}-2 D S \cos \theta+S^{2}\right)^{\frac{1}{2}}}\right]
$$

and

$$
\gamma_{c}=\sin ^{-1}\left[\frac{D \sin \gamma-S \sin \gamma_{s}}{\left(D^{2}-2 D S \cos \theta+S^{2}\right)^{\frac{1}{2}}}\right] .
$$

A most interesting conclusion emerges from this analysis: An ability to integrate information $(D, \theta$, and $S)$ which is determinative of $\theta_{c}$, is required for the determination of $\gamma_{c}$ as well. If Phidippus can determine $\gamma_{c}$ with some accuracy, then it must also have the requisite information for the determination of $\theta_{c}$ with a similar accuracy. Thus route-referent orientation plays an imperative role in compensation for movement within the gravity-referent system. By similar analysis, an appraisal of the new prey distance $\left(D_{c}\right)$ is also implicit in the ability to determine $\gamma_{c}$ :

$$
D_{c}=\left(D^{2}-2 D S \cos \theta+S^{2}\right)^{\frac{1}{2}} .
$$

Again this analysis leads to a most interesting conclusion, since $D_{c}$, in concert with the two directional components $\left(\gamma_{c}\right.$ and $\left.\theta_{c}\right)$, completes the definition of the prey position. If Phidippus can determine an accurate approximation of $\gamma_{c}$, then it must also have all of the information required to determine the actual position of the prey with a similar accuracy. This interpretation agrees with the observed ability of Phidippus to execute accurate, and direct, reorientation turns in space.

One can conclude that the available reference systems for the determination of prey direction are not employed independently during the pursuit. Each form of information available to the spider can be considered to contribute to at least the functional equivalent (discerned from behavior) of an integrated world view based upon the fixity of three-dimensional space, irrespective of movement within that space.

\section{The Mechanism of Route-Referent Orientation}

It has been shown (Fig. 4B) that accurate reorientation did not require any form of visual feedback. An imperative question, then, is the explicit nature of the 
information used by the spider as it orients with reference to the direction of pursuit. The ability of salticids to face sighted prey in the absence of visual feedback (Land, 1971) clearly demonstrates a close relationship between internalized directional information and the coordinated execution of a corresponding turn by the spider. It is possible that route-referent information is acquired in a related, but inverted, manner: The execution of a directed turn (toward the route) may be the source of this information. The role of $\theta$ (initial route-referent orientation) as a determinant of $\theta_{r}$ (route-referent reorientation) may be compared with the general ability of arthropods to compensate for a forced turn with a reverse turn when allowed to do so, in order to maintain a course (Akre, 1964; Wilson and Hoy, 1968; Burger, 1971; Schäfer, 1975a and b).

Mittelstaedt-Burger (1972) proposed a classification of oriented behavior into its respective allothetic (based upon the use of external references) and idiothetic (internal references) components. In general the direction of the route (allothetic reference) and the axis of the prosoma (idiothetic reference) are in alignment during pursuit, and both can contribute to the use of the route as a reference direction.

\section{Comparison with Other Spiders}

For this study, a segment of indirect pursuit provided the behavioral context for the study of salticid orientation. It appears that the execution of a distinct reorientation to face the prey position during indirect pursuit is uniquely a feature of salticid behavior, among the chelicerates. This is clearly related to the extraordinary use of vision by spiders of this family.

Apart from its behavioral context, however, the information used by the salticid to orient in space compares with that used by both agelenids and araneids to orient within their webs. These web spiders are known to employ idiothetic route-referent information (Holzapfel, 1933; Görner, 1958; Moller, 1970), gravity-referent information (Bartels, 1929; Peters, 1932; Holzapfel, 1933; LeGuelte, 1969; Robinson, 1969) and visual cues (Bartels and Balzer, 1928; Bartels, 1929; Peters, 1932; Görner, 1958, 1966; Dornfeldt, 1975a and b) to determine direction. Like the salticid Phidippus, the agelenid Agelena (Dornfeldt, 1975b) and the ctenid Cupiennius (Barth, 1976) can also retain information with regard to the distance of their movement during a short foray in pursuit of prey.

The apparent inability of Phidippus to utilize patterns of sky polarization (Table 2, series D) does not conform with results obtained with other spiders, including the agelenid Agelena (Görner, 1958, 1962, 1966), the lycosid Arctosa (Papi, 1955, 1959), and the theraphosid Eurypelma (Henton and Crawford, 1966), which do employ this information in the context of astromenotaxis.

Land (1969a) suggested that the anterior medial eyes (AME) of salticids might contain receptors capable of detecting the plane of polarized skylight, although there is no behavioral or physiological evidence to this effect at present. It is possible that the specialization of the salticid AME for purposes of high resolution (form vision) has taken precedence over the potential (and perhaps more primitive) role of these eyes in the detection of polarization 
patterns. In this regard, the $\mathrm{AME}$ of salticids have a very restricted field of vision (Land, 1969a and b), when compared with those of other spiders, and they are seldom directed toward the sky during a pursuit. Of course there is always a possibility that some undiscerned applications for the ability to discern the plane of polarized light do exist in the behavioral repertoire of salticids.

\section{The Use of Detours}

Most of the published descriptions of predatory pursuit by salticid spiders (Homann, 1928; Drees, 1952; Gardner, 1964, 1965; Forster, 1977) are based upon the observation of captive salticids upon flat, horizontal surfaces. On such a surface, a salticid will pursue and stalk its prey directly. Nonetheless it is really quite easy to demonstrate the ability of these animals to conduct a detoured pursuit.

Several field observations of the author should serve to illustrate the importance of this ability to the salticid spider, quite apart from the context of predatory pursuit. In one instance an immature Phidippus princeps was observed during a period of 'active search', characterized by intervals of movement frequently interrupted by bouts of visual survey (execution of a series of turns in place). After stopping to survey (sustained facing) a cluster of the leaves of Euphorbia esula, this spider quickly ran a detour to this apparent objective, and subsequently used the leaves to support its molting sac. An adult male P. audax conducted an extensive detour, interrupted by bouts of visual courtship display at the onset, in pursuit of a female of the same species sighted at a distance of $20 \mathrm{~cm}$. Visual survey of the environs is a major activity of these spiders; presumably this survey is employed by the spider to locate its objectives, which may then be attained by means of a detour should this prove necessary.

A number of vertebrate predators are reported to employ detours during their pursuit of prey (Curio, 1976). Land (1974) described the remarkable evolutionary convergence of salticid vision with that of a predatory mammal; given the constraints of environmental geometry, there is good reason to believe that the basic features of detoured pursuit, as conducted by salticids and vertebrates, are very similar.

Bees can retain a memory of the relative direction of either their hive or a feeding station, which compensates for their own nonlinear movement (von Frisch, 1967). The ability of a bee or wasp to conduct a foraging expedition may be compared with the ability of a salticid to conduct a detour in pursuit of prey: In each case, visual information is a significant determinant of the immediate direction of movement, and a requisite memory of the relative direction of a 'primary objective' (either the colony, or the prey position, respectively) must be corrected for the movement of the animal.

Acknowledgements. This study was completed as part of a doctoral dissertation at the University of Florida. I thank Dr. Jonathan Reiskind, Dr. John F. Anderson, and Dr. James E. Lloyd of that institution for the encouragement and criticism which they provided during the course of this study. Dr. David B. Richman of New Mexico State University and Dr. G.B. Edwards of the Florida Division of Plant Industry assisted in the collection and identification of spiders. Completion of the manuscript was a direct result of the support and encouragement of Dr. Thomas Eisner. 


\section{References}

Akre, R.D.: Correcting behavior by insects on vertical and horizontal mazes. J. Kans. Entomol. Soc. 37, 169-186 (1964)

Bartels, M.: Sinnesphysiologische und psychologische Untersuchungen an der Trichterspinne Agelena labyrinthica (Cl.). Z. Vergl. Physiol. 10, 527-593 (1929)

Bartels, M., Baltzer, F.: Über Orientierung und Gedächtnis der Netzspinne Agelena labyrinthica. Rev. Suisse Zool. 35, 247-258 (1928)

Barth, F.G.: Sensory information from strains in the exoskeleton. In: The insect integument. Hepburn, H.R. (ed.), pp. 445-473. Amsterdam: Elsevier 1976

Burger, M.L.: Zum Mechanismus der Gegenwendung nach mechanisch aufgezwungener Richtungsänderung bei Schizophyllum sabulosum (Julidae, Diplopoda). Z. Vergl. Physiol. 71, 219-254 (1971)

Crome, W.: Arachnida. In: Exkursionsfauna, Wirbellose I. Stresemann, E. (ed.), pp. 289-361. Berlin: Volk und Wissen 1957

Curio, E.: The ethology of predation, pp. 1-250. Berlin, Heidelberg, New York: Springer 1976

Dornfeldt, K.: The role of the principal and accessory eyes in the photomenotactic orientation of the funnel spider Agelena labyrinthica (Cl.). Z. Tierpsychol. 38, 113-153 (1975a)

Dornfeldt, K.: The control system of homing in the spider Agelena labyrinthica (Cl.). Z. Tierpsychol. 38, 267-293 (1975b)

Drees, O.: Untersuchungen über die angeborenen Verhaltenweisen bei Springspinnen (Salticidae). Z. Tierpsychol. 9, 169-207 (1952)

Duelli, P.: Movement detection in the posterolateral eyes of jumping spiders (Evarcha arcuata, Salticidae). J. Comp. Physiol. 124, 15-26 (1978)

Forster, L.M.: A qualitative analysis of hunting behavior in jumping spiders (Araneae: Salticidae). N.Z. J. Zool. 4, 51-62 (1977)

Frisch, K. von: The dance language and orientation of bees, pp. 1-566. Cambridge, Mass.: Belknap Press 1967

Gardner, B.T.: Hunger and sequential responses in the hunting behavior of salticid spiders. J. Comp. Physiol. Psychol. 58, 167-173 (1964)

Gardner, B.T.: Observations on three species of Phidippus jumping spiders (Araneae: Salticidae). Psyche 72, 133-147 (1965)

Görner, P.: Die optische und kinästhetische Orientierung der Trichterspinne Agelena labyrinthica. Z. Vergl. Physiol. 41, 111-153 (1958)

Görner, P.: Die Orientierung der Trichterspinne nach polarisiertem Licht. Z. Vergl. Physiol. 45, 307-314 (1962)

Görner, P.: U̇ber die Koppelung der optischen und kinästhetischen Orientierung bei der Trichterspinne Agelena labyrinthica (Clerck) und Agelena gracilens C.L. Koch. Z. Vergl. Physiol. 53, 253-276 (1966)

Heil, K.H.: Beiträge zur Physiologie und Psychologie der Springspinnen. Z. Vergl. Physiol. 23, 1-25 (1936)

Henton, W.W., Crawford, F.T.: The discrimination of polarized light by the tarantula. Z. Vergl. Physiol. 52, 26-32 (1966)

Holzapfel, M.: Die nicht-optische Orientierung der Trichterspinne Agelena labyrinthica (Cl.). Z. Vergl. Physiol. 20, 55-116 (1933)

Homann, H.: Beiträge zur Physiologie der Spinnenaugen. II. Das Sehvermögen der Salticiden. Z. Vergl. Physiol. 7, 229-268 (1928)

Kästner, A.: Reaktion der Hüpfspinnen (Salticidae) auf unbewegte farblose und farbige Gesichtsreize. Zool. Beitr. 1, 12-50 (1950)

Land, M.F.: Structure of the retinae of the principal eyes of jumping spiders (Salticidae: Dendryphantinae) in relation to visual optics. J. Exp. Biol. 51, 443-470 (1969a)

Land, M.F.: Movements of the retinae of jumping spiders (Salticidae: Dendryphantinae) in response to visual stimuli. J. Exp. Biol. 51, 471-493 (1969b)

Land, M.F.: Orientation by jumping spiders in the absence of visual feedback. J. Exp. Biol. 54, 119139 (1971)

Land, M.F.: A comparison of the visual behavior of a predatory arthropod with that of a mammal. In: The neurosciences: Third study program. Schmitt, F.O., Worden, F.G. (eds.), pp. 411-418. Cambridge, Mass.: MIT 1974 
LeGuelte, L.: Learning in spiders. Am. Zool. 9, 145-152 (1969)

Mendenhall, W., Scheaffer, R.L.: Mathematical statistics with applications, pp. 1-561. North Scituate, Mass.: Duxbury 1973

Mittelstaedt-Burger, M.L.: Idiothetic course control and visual orientation. In: Information processing in the visual systems of arthropods. Wehner, R. (ed.), pp. 275-279. Berlin, Heidelberg, New York: Springer 1972

Moller, P.: Die systematischen Abweichungen bei der optischen Richtungsorientierung der Trichterspinne Agelena Labyrinthica. Z. Vergl. Physiol. 66, 78-106 (1970)

Papi, F.: Astronomische Orientierung bei der Wolfspinne Arctosa perita (Latr.). Z. Vergl. Physiol. 37, 230-233 (1955)

Papi, F.: Sull' orientamento astronomico in specie del gen. Arctosa (Araneae, Lycosidae). Z. Vergl. Physiol. 41, 481-489 (1959)

Peters, H.: Experimente über die Orientierung der Kreuzspinne Epeira diademata Cl. im Netz. Zool. Jahrb. Abt. Allg. Zool. Physiol. Tiere 51, 239-288 (1932)

Robinson, M.H.: Predatory behavior of Argiope aurantia. Am. Zool. 9, 161-173 (1969)

Runyon, R.P., Haber, A.: Fundamentals of behavioral statistics, pp. 1-351. Reading, Mass.: Addison-Wesley 1971

Schäfer, M.W.: Gegendrehung und Winkelsinn in der Orientierung von Lithobius forficatus L. Teil I. Nachweis der Winkelsinne, Charakterisierung der Orientierungsleistung. Behaviour 55, 15-41 (1975a)

Schäfer, M.W.: Gegendrehung und Winkelsinn in der Orientierung von Lithobius forficatus L. Teil II. Die äußeren und inneren Bezugspunkte. Behaviour 55, 42-72 (1975b)

Wilson, D.H., Hoy, R.R.: Optomotor reaction, locomotory bias and reactive inhibition in the milkweed bug Oncopeltus and the beetle Zophobas. Z. Vergl. Physiol. 58, 136-152 (1968) 